
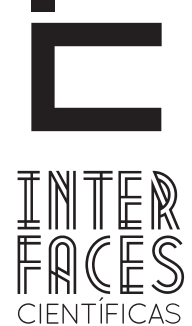

DIREITO

\title{
A SISTEMATIZAÇÃO DOS DIREITOS FUNDAMENTAIS FRENTE SUAS CRESCENTES VIOLAÇÕES POR MEIO DO USO DA INTERNET
}

\section{RESUMO}

Terá o presente artigo, a função de demonstrar os problemas advindos com o avanço tecnológico da Internet em rota de colisão junto ao direito à intimidade de seus respectivos usuários. Demonstrando assim que a Internet tornou-se um espaço extremamente amplo de modo que carece de uma proteção quanto aos direitos de seus usuários, que depositam inúmeros dados pessoais nestas redes. Sendo também objeto do presente estudo a sistematização dos direitos fundamentais, que encontram-se positivados em nossa Carta Maior, que visam estabelecer direitos, deveres e garantias entre os cidadãos, bem como o direito à intimidade que muitas vezes é violado decorrente das práticas destas condutas acima descritas, e ainda trataremos do direito a informação. Será também objeto de análise a criação e o funcionamento da Internet, bem como suas funções e os principais serviços oferecidos aos seus usuários. Tratando-se ainda dos delitos oriundos dos meios informáticos classificados estes como crimes virtuais próprios e impróprios. Abordando assim, a problemática existente entre a percepção e o respeito ao direito à intimidade e, inevitavelmente, a presença cada vez mais constante, das novas tecnologias na época em que nos encontramos.

\section{PALAVRAS-CHAVE}

Direito à intimidade. Direitos e garantias fundamentais. Vida Privada e Intimidade. Internet. Crimes virtuais. 


\section{ABSTRACT}

Has the present article, the function of showing the problems that come with advancing technology of the Internet on a collision course with the right to privacy of their users. Thus demonstrating that the Internet has become an extremely wide space so it lacks protection for the rights of its members, who put countless personal data in these networks. Being also the object of this study systematization of fundamental rights, which are positivized in our Magna Carta, which aim to establish rights, duties and guarantees among citizens as well as the right to privacy is often violated due to the practices of these behaviors described above, and still treat the right to information. It will also be the object of analysis the creation and operation of the Internet, as well as its main functions and services offered to its users. In the case of further offenses arising from these computer resources classified as cybercrime proper and improper. Thereby addressing the problem between perception and respect the right to privacy and, inevitably, the presence increasingly steady, new technologies at the time we met.

\section{KEYWORDS}

Right to Privacy. Fundamental Rights and Guarantees. Privacy and Intimacy. Internet. Cybercrime.

\section{RESUMEN}

Tiene el presente artículo, la función de demostrar los problemas que vienen surgiendo con el avance de la tecnología del Internet en un curso de colisión con el derecho a la privacidad de sus usuarios. Así, lo que demuestra es que el Internet se ha convertido en un espacio muy amplio que carece de la protección de los derechos de sus miembros, que por su vez, suelen poner un sinnúmero de datos personales en estas redes. Siendo también objeto de este estudio la sistematización de los derechos fundamentales, que están en nuestra Carta Mayor que visan establecer los derechos, deberes y garantías a los ciudadanos, así como, el derecho a la privacidad que es violada a todo momento, debido a las prácticas de estos comportamientos descritos anteriormente, y aún tratar del derecho a la información. También será objeto de análisis la creación el funcionamiento de Internet, así como sus principales funciones y servicios que son ofrecidos a sus usuarios. Y el artículo, aun trata de otros delitos derivados de estos recursos informáticos clasificados como delitos cibernéticos propio e impropio. Abordando así, el problema entre la percepción y el respeto al derecho a la intimidad e, inevitablemente, la presencia cada vez más constante de las nuevas tecnologías en el momento que nos conocimos.

\section{PALABRAS CLAVE}

Derecho a la Privacidad. Derechos y Garantías Fundamentales. Privacidad y la Intimidad. Internet. Ciberdelincuencia. 


\section{INTRODUÇ̃̃̃O}

0 presente trabalho se inicia tratando da uma mera exposição acerca dos direitos e garantias fundamentais, que se encontram positivados em nossa Constituição Federal de 1988.

Em seguida, passa a relatar sobre o direito à intimidade, um dos temas centrais do presente trabalho, que se trata de uma garantia de ordem constitucional à vida privada de todo cidadão, conforme o disposto no artigo $5^{\circ} \mathrm{X}$, da Constituição Federal Brasileira.

Na sequência, a pesquisa irá tratar da evolução histórica da Internet, bem como o seu completo e amplo funcionamento. Levando em consideração que inevitavelmente a Internet está presente de modo constante em nossas vidas, o que leva diretamente ao choque entre direitos pertencentes aos seus usuários, tendo como base que todo cidadão possui à sua vida

\section{DIREITOS FUNDAMENTAIS}

\subsection{CONCEITO}

Em linhas gerais, direitos e garantias fundamentais seriam os direitos indispensáveis para que toda e qualquer pessoa possa vir a viver dignamente.

Direitos e garantias fundamentais possuem como finalidade primária o estabelecimento de direitos, garantias e deveres perante os cidadãos, sistematizando assim noções que servem como base para a regularização de todo aspecto social, político e histórico da vida em sociedade, possuindo também a finalidade de resguardar a dignidade da pessoa humana em qualquer que sejam as suas dimensões. privada, intima e que deseja profundamente que esta jamais seja violada ou extirpada por terceiros.

Diante da necessidade e da importância do uso praticamente diário dos meios eletrônicos, entendemos assim pela Internet, pessoas estão usualmente tendo seus direitos violados, mais precisamente seu direito à intimidade, devido também à exposição de suas vidas na Internet, o que muitas vezes ocorre sem o consentimento de seus titulares.

E por fim, será feito uma breve exposição acerca da responsabilidade civil do autor da lesão, bem como a dificuldade de se chegar à autoria do delito, e também será analisada a responsabilidade do fornecedor do acesso à Internet.

Enfim, em linhas gerais, serão estes os principais tópicos e assuntos a serem tratados no respectivo trabalho.

O ordenamento jurídico brasileiro utiliza-se da expressão "direitos fundamentais", conforme disposto em nossa Carta Maior. Entretanto, Luiz Alberto David Araujo (2003), que trata do tema, emprega diferentes denominações, tais como: direitos humanos, liberdades assecuratórias, liberdades públicas.

Mas a doutrina, partidária em sua maioria do pensamento de Luiz Alberto David Araujo (2003, p.86) e Paulo Bonavides (2003), tem por entendimento predominante, que a expressão "direitos fundamentais" é a mais adequada para o tratamento destas garantias. 
Não podendo deixar de ser citada, a conceituação dada por Alexandre de Moraes (1997, p.39) acerca do tema:

Os direitos fundamentais têm por finalidade básica, o respeito à dignidade do ser humano, por meio de sua proteção contra 0 arbítrio do poder estatal e o estabelecimento de condições mínimas e desenvolvimento da personalidade humana.

Deste modo, entende-se por direitos e garantias fundamentais, regras básicas atinentes a toda sociedade que almeje uma harmonia entre seus singulares, estabelecendo assim direitos e deveres que devem ser respeitados a qualquer custo.

\subsection{ORIGEM E EVOLUÇ̃̃O DOS DIREITOS FUNDAMENTAIS}

Os primeiros indícios de que surgiram mecanismos para a proteção individual deram-se no Egito e na Mesopotâmia, baseados no Código de Hamurabi, sendo assim, o primeiro indício da positivação destes direitos, quais sejam: direito à vida, dignidade, propriedade, prevalecendo estes frente aos governantes da época, o que foi um tremendo avanço.

Neste período nasce a filosofia, que muito contribuiu para a positivação destes direitos, haja vista que substitui o saber mitológico pelo saber lógico da razão assim, passa o homem a ser objeto de reflexão, estabelecendo-se assim os primeiros princípios e diretrizes fundamentais de toda vida em sociedade.

0 processo de positivação dos direitos humanos deu-se ainda na Idade Média, mais precisamente com a Magna Carta de 1215, que foi criada com a finalidade de acabar com os poderes ilimitados tanto dos reis quanto do papado, cessando-se assim os inúmeros conflitos existentes na época, sendo esta a primeira fonte das chamadas Declarações de Direitos Fundamentais, que com o passar dos anos, foi deixando de ser apenas reivindicações políticas e tornaram-se nor-
Por fim, é de suma importância estabelecer a diferença entre direitos fundamentais e direitos humanos, haja vista que encontra certa diferenciação na doutrina.

Direito fundamental compreende aqueles direitos que encontram-se positivado, ou seja, estão devidamente previstos em lei de forma imperativa.

Já os direitos humanos, são os direitos de ordem subjetiva, ou seja, aqueles que valem por si só, não possuindo previsão legal, mas que existem no consciente de todo ser humano, mais precisamente como uma regra moral.

mas jurídicas em razão de sua constitucionalização.

Com o fim da segunda Grande Guerra em 1945, já no ano de 1948 surge a Declaração Universal dos Direitos do Homem, com a finalidade de combater as atrocidades praticadas naquela, contra a dignidade da pessoa humana.

Diante de todo o exposto, contata-se a dificuldade de se estabelecer um marco inicial aos Direitos Fundamentais. Diante disso, se faz por necessário a descrição dos pensamentos de Norberto Bobbio (1992, p.21):

Os direitos humanos positivados não derivam do estado de natureza, o qual foi utilizado apenas como argumento para justificar racionalmente determinadas exigências do homem. Segundo ele, o real surgimento de alguns direitos deriva das lutas e movimentos travados pelos homens cujas razões devem ser buscadas na realidade social da época, e não no estado de natureza, pois este revela a hipótese abstrata de um estado simples, primitivo, onde o homem vive com poucos carecimentos essenciais, oposto ao mundo de onde derivou toda a gama de Direitos Fundamentais que hoje conhecemos. 
Conclui-se, portanto, que dizer que houve um marco inicial e específico para a criação dos Direitos Fundamentais não é tarefa fácil, haja vista uma de suas principais características: a imutabilidade.

\subsection{DIREITO À INTIMIDADE}

\subsubsection{CONCEITO}

0 direito à intimidade configura-se um direito fundamental, ao qual confere ao indivíduo enquanto cidadão, o direito de se resguardar de ações praticadas por terceiros contra a sua pessoa, mais precisamente resguardando sua esfera íntima e privada.

Trata-se de um direito que possui significativas características de mutabilidade, visto que encontra-se sempre em constantes modificações, levando-se em conta os aspectos históricos e sociais aos quais estão sujeitos.

Há certa complexidade em determinar o que vem a ser "intimidade", pois para que seja feita uma relevante definição, deve-se levar em conta o lugar, a época, bem como os valores sociais, morais e políticos de cada período.

\subsubsection{GARANTIA CONSTITUCIONAL}

0 direito à intimidade foi promovido à garantia de ordem constitucional, visando assim à proteção do maior bem que qualquer pessoa pode possuir a vida. De modo que se protege a vida pessoal de todo e qualquer individuo, que só poderá ser revelada ou divulgada com a devida permissão deste.

0 direito à intimidade encontra-se descrito no artigo $5^{\circ}, X$ da Constituição Federal:
Mas, o marco mais aceito pelos historiadores do tema trata-se de seu surgimento na Idade Média, com o cristianismo, haja vista que esta doutrina apontava a igualdade do homem a Deus, sendo este um dos primeiros esboços da concessão de direitos aos cidadãos da referida época.

Diante disto, verifica-se que a intimidade possui um caráter no que tange ao seu conteúdo muito amplo e extremamente variável, pois emprega certa dificuldade para que seja determinado com precisão.

Nesse sentido, encaixa-se perfeitamente a definição de Tércio Sampaio Ferraz, dizendo que não há um conceito absoluto que preceitue o direito à intimidade.

A intimidade trata-se, portanto, de um direito de personalidade, que por consequência possui características de irrenunciabilidade, sendo assim, nenhum indivíduo pode abrir mão em detrimento de seu direito, devendo assim resguardá-lo no seu mais profundo ímpeto. Pois a publicidade inevitavelmente supera a intimidade.

Art.50:

X-São invioláveis a intimidade, a vida privada, a honra e a imagem das pessoas, assegurando o direito à indenização pelo dano material ou moral decorrente de sua violação.

Sendo assim, toda vez que alguém tiver sua intimidade extirpada ou divulgada, terá o devido direito à indenização pelo dano sofrido, tanto no âmbito moral, quanto no material. 
0 direito à intimidade está entre os direitos humanos de ordem fundamental, positivados na Constituição Federal, denominados de "cláusulas pétreas". E

\subsubsection{INTIMIDADE E VIDA PRIVADA}

Tanto o direito à intimidade, quando o direito à vida privada são tutelados pela Constituição Federal, sendo assim, ambos guardam entre si grande vinculação.

Contudo, mesmo que seus conceitos se confundam, possuem características distintas, que podem ser objeto de diferenciação. Tais diferenças residem no fato de que a intimidade reside em um caráter mais interno, ou seja, um círculo mais restrito, diferente do direito à vida.

Para melhor entendimento do tema, faz-se por necessário a citação de Tércio Sampaio Ferraz (1992, p. 449):

A intimidade é o âmbito do exclusivo que alguém reserva para si, sem nenhuma repercussão social, nem mesmo ao alcance da sua vida privada que, por mais isolada que seja, é sempre um viver entre os outros (na família, no trabalho, no lazer comum). Não há um conceito absoluto de intimidade, embora se possa dizer que o seu atributo básico é o estar só, não exclui o segredo e a autonomia. Nestes termos, é possível identificá-la: o diário íntimo, o segredo sob juramento, as próprias convicções, as situações indevassáveis de pudor pessoal, o segredo íntimo cuja mínima publicidade constrange.

Sendo assim, pode-se entender que o direito à intimidade caracteriza-se pela esfera mais íntima de proteção à pessoa, tais como seus pensamentos, seus desejos e suas emoções.

Dizendo respeito ao modo de ser da pessoa, à sua identidade, sendo uma conceituação mais estrita da vida privada. Sendo o mais interior da pessoa, abrangendo um âmbito mais limitado, ligada a uma acepção devido a isso, não se admite, de maneira alguma, que este direito sofra qualquer medida extintiva ou modificativa.

estrita, à zona espiritual da pessoa.

Já a vida privada ou a privacidade, caracteriza-se pelo caráter mais amplo do que a intimidade, ou seja, tudo o que não transparece para a esfera pública, sendo as ligações com os indivíduos de caráter mais próximos, entende-se por relações familiares ou pessoas de contato diário.

Ou seja, a privacidade encontra-se resguardada por um caráter de maior abrangência subjetiva, de modo que o indivíduo estende os aspectos pessoas de sua vida para determinado grupo de pessoas, grupo 0 qual se encontra no convívio social da pessoa.

Faz-se de maneira oportuna a exposição do pensamento do doutrinador Tércio Sampaio Ferraz acerca do tema (1992, p. 450):

A vida privada pode envolver, pois, situações de opção pessoal (como a escolha do regime de bens no casamento), mas que, em certos momentos, podem requerer a comunicação a terceiros (na aquisição, por exemplo, de um imóvel). Por aí ela difere da intimidade, que não experimenta esta forma de repercussão.

Conclui-se, portanto, que de fato só a própria pessoa pode, pelo seu respectivo comportamento, estabelecer o âmbito e o limite de sua intimidade, entende-se assim o seu sentido mais estrito.

Por fim, a vida privada manifesta-se para o exterior, estando mais exposta e regida por regras e costumes de convivência social. 


\subsection{DIREITO À INFORMAÇÃO E À INTERNET}

Assegurado pela constituição federal, o direito à informação encontra-se previsto no art. $5^{\circ}$, inciso XXXIII, onde diz:

XXXIII - todos têm direito a receber dos órgãos públicos informações de seu interesse particular, ou de interesse coletivo ou geral, que serão prestadas no prazo da lei, sob pena de responsabilidade, ressalvadas aquelas cujo sigilo seja imprescindível à segurança da sociedade e do Estado.

Conforme o exposto acima, vivemos em uma sociedade onde perdura a máxima de que informação é poder. Deste modo, configura-se que a informação passa a ser um meio de formação de ideia e interpretação de pensamentos e também possibilitando a difusão de notícias, de acontecimentos, possuindo assim importância fundamental na sociedade atual.

A problemática reside quando tratamos de dados pessoais, que são exigidos pelo Estado para um efetivo controle da máquina estatal, que na maioria das vezes são dados atinentes à vida pessoal dos cidadãos. Com o passar do tempo, foi adotada pelo Estado a digitalização destes dados pessoais, ou seja, foram todos armazenados nos bancos de dados do governo, o chamado tratamento automatizado da informação pessoal.

Deste modo, a intimidade das pessoas possui maior vulnerabilidade, vez que se encontra livremente disponível da Internet, e em certas mídias sociais.

0 direito de informação encontra-se pautado em 03 (três) vertentes básicas, quais são: o direito de informar, o direito de ser informado e o direito de se informar.

O direito de informar consiste na liberdade de transmissão das informações, ou seja, certos meios que tem como finalidade transmitir qualquer tipo de informação.

O direito de se informar possui como escopo o direito que todo e qualquer cidadão possui de receber as informações que pretende.

E por fim, o direito de ser informado surge no momento em que alguém possui um dever de informar, como podemos verificar nos órgãos públicos tal dever.

Em um mundo contemporâneo, onde as informações encontram-se basicamente situadas nos meios eletrônicos, o exercício do direito à informação deve ser realizado por meios de pesquisas eletrônicas na rede, para que isto não configure uma violação da privacidade ou de eventual sigilo que possua a respectiva informação.

Alguns dados, como o sigilo fiscal, bancário, telefônico e até mesmo prontuários médicos possuem caráter sigiloso, devendo assim ser respeitados sob pena de invasão à privacidade e exposição da vida privadas de algumas pessoas.

Conclui-se, portanto, que direito à informação é direito que todo e qualquer cidadão possui, de poder consultar eventuais informações albergadas na Internet, pois na maioria das vezes tais informações possuem caráter publico, haja vista que encontram-se em um meio extremamente difundido e público.

Em suma, todos os cidadãos pertencentes a um Estado democrático de direito possuem o direito de se informar de eventuais dados necessários pertencentes a outros cidadãos, mas sempre levando-se em conta que certos limites devem ser respeitados, para que não ocorra a deturpação deste direito. 


\section{A INTERNET}

\subsection{A HISTÓRIA DA INTERNET}

A internet surgiu a partir de pesquisas militares nos períodos pertencentes à Guerra Fria, em uma época em que qualquer inovação deste caráter poderia ser decisiva para a batalha em que encontravam-se União Soviética e Estados Unidos da America.

Deste modo, o governo dos Estados unidos temia que suas bases militares fossem atacadas e assim, com este ataque, suas informações de caráter extremamente sigiloso poderiam vir à tona. Devido a isso, havia a necessidade de se criar um mecanismo que difundisse, espalhasse estas informações, para que não fossem encontradas todas juntas em eventuais ataques militares.

Dessa forma, criou-se uma rede denominada de Arpanet, que funcionava a partir de um sistema de codificação ou de chaveamento, onde as informações transmitidas eram armazenadas em pacotes distintos, podendo ainda ser conectada a redes de outros países.

Na prática, o ataque temido jamais ocorreu, mas tudo isso contribuiu para o surgimento do maior fenômeno midiático no século 20 , que conseguiu atingir

\subsubsection{UMA BREVE ABORDAGEM ACERCA DO FUNCIONAMENTO DA INTERNET}

Entender o que é e como funciona a Internet faz-se por imprescindível para que seja feito qualquer desenvolvimento de um trabalho atinente à proteção jurídica necessária de um direito nesta seara, no caso, o direito à intimidade.

A Internet não é apenas uma rede de computadores interligados, mas sim uma rede em caráter mundial de computadores, que se comunicam através de proto- cerca de 50 milhões de pessoas no mundo.

No Brasil, a internet surgiu a partir do ano de 1987, onde realizou-se uma reunião entre Governo e a Embratel, com o objetivo de criar-se uma rede que possibilitasse a interação entra a comunidade cientifica e acadêmica do Brasil com outros países, com o fim de compartilhar informações.

No ano de 1988, o Laboratório Nacional de Computação Científica conseguiu se conectar à Universidade de Maryland, de modo que possibilitou a troca de mensagens entre estas instituições.

Por fim, no ano de 1955 realizou-se a primeira transmissão de longa distância entre os estados brasileiros e após isto, foi liberada a operação comercial no Brasil, permitindo assim ao setor privado os acessos à internet para fins de exploração comercial no Brasil.

Assim sendo, a Internet ganhou vida em nosso dia a dia, e cada vez tornando-se mais presente como ferramenta de trabalho, informações, comunicações e entretenimento.

colos TCP/IP (Transmission Control Protocol / Internet Protocol)

Segundo Marcelo Cardoso Pereira (2006, p. 38):

A Internet é uma rede de computadores formada por milhões de outras redes, e tendo em vista que tanto os computadores como as redes comunicam-se 
obedecendo a determinados protocolos, é necessário por que não dizer obrigatório, que façamos uma aproximação aos protocolos mais importantes que permitem o funcionamento técnico da Rede (TCP/IP, HTTP, WWW, HTML).

0 protocolo TCP/IP consiste basicamente em um programa que fragmenta em partes uma mensagem enviada de um computador para outro, para que possa ser transferida pela Rede, até seu destino. O protocolo TCP então é o responsável de organizar, transportar, fragmentar e supervisionar as informações através da internet e ainda, se algo se perde durante este processo, ele será o encarregado de proceder o reenvio da parte que se perdeu.

Já o protocolo IP, se diferencia do endereço IP, um dos mais conhecidos assuntos na Internet, que consiste em toda vez que firmamos um contrato de aces-

\subsection{ALGUNS SERVICOSS OFERECIDOS PELA INTER- NET}

\subsubsection{WORLD WIDE WEB [WWW]}

O surgimento da World Wide Web ocorreu no ano de 1992, mais precisamente no mês de janeiro deste mesmo ano, através do chamado FPT anônimo, programa este necessário para o acesso à web, sendo os navegadores padrões conhecidos por todos atualmente.

A partir daquele momento, a WWW encontrava-se disponível para qualquer pessoa acessá-la.

Atualmente, o prenome WWW é de conhecimento notório, constituindo-se basicamente na união de dois fatores imprescindíveis, quais sejam: o hipertexto e internet, sendo considerada pelo estudioso Berners- so com a Rede, surge um numero que passará a ser o nosso endereço na de Rede, nosso endereço IP, possuindo assim cada máquina seu número de identificação, que jamais será igual a qualquer outro número.

O protocolo IP, por sua vez, possui a função de estabelecer os endereços de origem e de destino de cada uma das partes, pois o protocolo TCP não sabe a qual computador enviar as informações desejadas.

O protocoo HTTP consiste basicamente na transferência de informações entre o usuário e o servidor de Internet, e vice-versa. Quando inserimos uma URL (meio de se localizar servidores existentes na Internet) em nosso servidor, este se encarrega de enviar o respectivo pedido ao servidor web, solicitando alguma informação que encontra-se depositada na Rede, que no final resultará na página da web conhecida por todos os usuários da Internet.
-Lee, a ferramenta mais importante de toda a Rede mundial de computadores.

Marcelo Cardoso Pereira (2006, p. 53) explica sucintamente o funcionamento básico da Internet (web):

O protocolo HTTP, o qual, já se sabe, trata-se do protocolo de comunicação utilizado no âmbito da web. Assim, o que o navegador foi, com base em um endereço da Internet (um URL, como dito anteriormente), solicitar ao servidor web uma determinada informação, arquivo, enfim, uma página web. Gravadas ao protocolo HTTP, a solicitação é enviada desde um computador a um determinado servidor web, que, em 
seguida, e uma vez que seja um endereço URL válido, enviará a informação solicitada até o browser, o qual será responsável de ler as instruções HTML e apresentar na tela do computador a cópia da página web que fora solicitada inicialmente.

Sendo assim, pode-se afirmar que a web é uma tecnologia que nos permite acesso a documentos de hipertexto, para que possam ser recuperadas informações nos servidores web.

\subsection{POR QUE A INTERNET OFERECE PERIGO PARA A INTIMIDADE DE SEUS USUÁRIOS}

Atualmente, a Internet passou a figurar como um dos principais meios, senão o principal meio de interação entre pessoas. Além disso, possui característica de ferramenta essencial em nossas vidas, pois, é por meio dela que realizamos buscas do que desejamos, nos relacionamos, trabalhamos, efetuamos pagamentos, ou seja, quase tudo é realizado na seara virtual.

Marcelo Cardoso Pereira (2006, p. 146) nos explica bem os "rastros" e informações que deixamos depositadas na Rede, que pode acarretar para nós inúmeros prejuízos, conforme segue:

A maioria dos serviços disponíveis na Internet centra-se no modelo cliente/servidor (envio de solicitações e recebimento de respostas). Isso resulta que “mover-se” pela Rede signifique interação. Quando um usuário se conecta à Internet e começa a "locomover-se" por ela, vai deixando muitos "rastros" (dados e informações, de caráter pessoal ou não) por onde passa (páginas web, mailing, list, grupo de News etc.).

Partindo desta premissa, constata-se que não somente o usuário pode consultar dados e informações de seu interesse, mas também, outros inter-
Deste modo, está devidamente evidenciado que a WWW, com o devido auxílio dos navegadores, permite aos usuários de Internet acessar os documentos desejados, conhecidos como páginas na web.

Por fim, cabe ainda ressaltar que há a possibilidade de haver violação ao direito dos usuários, mais especificadamente o direito à intimidade na própria Web, que será objeto de estudo seguinte.

naturas também podem ter acesso a seus dados e informações.

Há de se ressaltar ainda, que há outro fator que evidencia o caráter de vulnerabilidade da Internet, facilitando assim atentados e o furto de informações e dados pessoais confidenciais. São os chamados bugs, que acabam por facilitar o acesso de pessoas de má-fé a dados pessoais de terceiros para fins delitivos.

Deste modo, os usuários da Rede são alvos fáceis de manipulações, furtos de dados pessoais para utilização em fins ilícitos e ainda passiveis de discriminações seja de ordem social, cultural ou religiosa, de modo que fica muito difícil impedir que tais ataques sejam realizados.

Dessa forma, todo e qualquer usuário que se conecte à Internet, mediante computador privativo, se transformará em uma potencial vítima de abusos na seara de sua intimidade.

Faz-se por necessário destacar que, conforme há uma maior incidência da tecnológica e também uma dependência direta desta para que seja possível a rea- 
lização de atividades diárias, consequentemente este espaço se torna um ambiente muito atrativo para o cometimento de crimes.

No mais das vezes, estas condutas são obras arquitetadas pelos denominados hackers que utilizam o meio informático como ferramenta essencial do delito, que são conhecidos como os crimes próprios de informática. Ou ainda, o meio informático é utilizado de maneira aleatória, ou seja, poderia ser qualquer outro meio para a prática da conduta criminosa, todavia, o meio escolhido foi o informático.

Em seguida, serão citadas algumas das práticas mais comuns no que tange aos crimes próprios advindo do meio informático. São eles: acesso não autorizado; obtenção e transferência ilegal de dados; dano informático; disseminação de vírus; divulgação ou uti-

\section{CONCLUSÃO}

Como constatado no presente trabalho, a Internet chegou em nossas vidas como um objeto de grande valia e de extrema necessidade dos dias de hoje, contudo, trouxe consigo grande problemas.

Um de seus maiores problemas reside na ideia do anonimato e do caráter de impunidade, tendo em vista os causadores de delitos por meio da Internet. Haja vista o livre acesso às redes de Internet e a facilidade da prática de crimes oriundos de meios digitais.

Outra problemática oriunda do crescente desenvolvimento dos meios digitais reside na ideia de apurar a responsabilidade penal em casos pontuais. Verificando assim, seus sujeitos ativos, que são denominados de hackers, devendo ser analisado o caráter da responsabilidade em tela, seja ela objetiva ou subjetiva. lização indevida de informações; embaraçamento ao funcionamento de sistemas e interceptação ilegal de dados.

Além dos crimes digitais próprios, existem também os delitos do meio informático denominados de impróprios. São eles: ameaça; participação em suicídio; incitação e apologia ao crime; falsa identidade e falsidade ideológica; violação de direitos autorais; pornografia infantil; crimes contra a honra. Estes são alguns dos delitos impróprios, praticados através do meio informático, o que nada impede que estes mesmos delitos sejam praticados por outros meios que não o digital. Sendo estes os delitos que já se encontram tipificados penalmente em nosso ordenamento jurídico, mas que são praticados por meio do auxílio da tecnologia da informática.

É de extrema relevância ponderarmos aqui que o direito à intimidade ao passo de que colida com a Internet, ou similares, deverá sempre prevalecer, levando-se em conta ainda a tutela concedida à vida privada e íntima de todo e qualquer cidadão, sendo que esta jamais poderá ser extirpada, sob nenhum aspecto.

Por fim, constatamos que o direito caminha a passos curtos, enquanto que os meios de comunicações e interações sociais caminham a passos longos, sendo assim, nem sempre teremos a devida proteção para eventuais práticas delituosas práticas a partir destes meios.

Por todo o exposto, fica evidente e necessária inovação legislativa, como já vem sendo feita, no sentido de ao menos tentar-se inibir ou coibir eventuais condutas criminosas, resguardando-se assim os direitos 
acima citados e que muitas vezes carecem da devida proteção jurídica.

Não há dúvida que com o advento da Lei $n^{\circ}$ $12.737 / 12$, houve um significativo avanço no sentido da tipificação de delitos praticados com o auxílio de meios de informática, tendo a presente lei a função de tipificar como condutas criminosas as ações de invasões de dispositivos informáticos sem prévia autorização do invadido; interrupção ou perturbação de serviço telegráfico, telefônico, informático, telemático ou de informações de utilidade pública e a falsificação de cartões de crédito.

Contudo, há de se ressaltar a extrema necessidade de novas leis que passem a tipificar condutas delituosas atinentes aos meios informáticos, devendo o direito acompanhar as mudanças sociais a que estamos sujeitos e, deste modo, que seja possível a positivação destas ações, com o objetivo de resguardar os direitos fundamentais de todos os cidadãos.

\section{REFERÊNCIAS}

ANDRADE, Allan Diego Mendes Melo. $\mathbf{O}$ direito à intimidade e à vida privada em face das novas tecnologias da informação. Disponível em (http://www.faete.edu.br/revista/ODIREITOAINTIMIDADE_E_\%20A_VIDA_PRIVADA_EM_FACEDASNOVASTECNOLOGIASDAINFORMACAO-Allan\%20Diego.pdf).

Acessado em 15 de março de 2013.

ARAUJO, Luiz Alberto David de. Curso de Direito Constitucional. 13a ed. São Paulo: Editora Saraiva. 2013.

BOBBIO, Norberto. A era dos direitos. $4^{\mathrm{a}}$ ed. Rio de Janeiro: Forense. 1992.

BONAVIDES, Paulo. Curso de Direito Constitucional. 28a ed. São Paulo: Editora Malheiros.2012.

CONSTITUIÇÃO, da República Federativa do Brasil de 1988.

FERRAZ, Tércio Sampaio. Sigilo de dados: direito à privacidade e os limites à função fiscalizadora do Estado. Cadernos de Direito Constitucional e Ciência Política. São Paulo. 1992.

MORAES, Alexandre de. Direitos fundamentais: teoria geral, comentários aos arts. $1^{\circ}$ a $5^{\circ}$ da Constituição da República Federativa do Brasil, doutrina e jurisprudência. $1^{a}$ ed. São Paulo.1997.

NOGUEIRA, Sandro D’amato. Crimes de Informática. 1ª ed. São Paulo : Editora BH. 2008.

PEREIRA, Marcelo Cardoso. Direito à intimidade na Internet. $1^{\mathrm{a}}$ ed : Juruá Editora. São Paulo.2006.

PARENTE, André. Tramas da rede: novas dimensões filosóficas, estéticas e políticas da comunicação. Porto Alegre: Sulina. 2004. 
1 Acadêmico do $7^{\circ}$ Termo do Curso de Direito da Associação Educacional Toledo de Presidente Prudente - SP

Aceito em: 11 de agosto de 2013

2 Mestre em Direito e professor do curso de Direito das Faculdades Inte-

gradas "Antonio Eufrásio de Toledo" de Presidente Prudente. marceloagamenon@unitoledo.br 